\title{
Research and Design of Cross Flow Water Turbines for Small HPP
}

\author{
Valentin Obretenov ${ }^{1 *}$ and Tsvetan Tsalov ${ }^{1}$ \\ ${ }^{1}$ Technical university of Sofia, department of Hydroaerodynamics and hydraulic machinery, 1000 \\ Sofia, Bulgaria
}

\begin{abstract}
This paper presents the experience of the Hydroaerodynamics and hydraulic machinery department of the Technical university of Sofia (Bulgaria) in the research and design of cross flow water turbines. The methods and computer programs used for the synthesis of the elements of the flow part of the cross flow turbines are described. Results of numerical and experimental (model and field) studies of turbines of this type are presented. The peculiarities of the elements of the designed turbines are analyzed and specific examples of their used in small hydropower plants in Bulgaria are shown.
\end{abstract}

\section{Introduction}

Cross flow turbines are used for heads from 2 to $200 \mathrm{~m}$, but their output is usually limited to $1000 \mathrm{~kW}$, because of comparatively low values of the efficiency (up to $85 \%$ ). In some cases, turbine power can reach up to $10000 \mathrm{~kW}$ [1]. The cross flow turbine has a number of advantages in terms of specific requirements for low power water turbines: it works with relatively high efficiency values (for this class of turbines) in a wide range of modes; it provides good manual and automatic control capabilities; the constructions are characterized by their relative simplicity, manufacturability and a high degree of unification of units and details; low cost.

The geographical and investment conditions in Bulgaria are very suitable for the use of this type of turbines in small hydropower plants [2]. This paper presents the experience of the department of Hydroaerodynamics and hydraulic machinery at the Technical university of Sofia in the research and design of cross flow turbines.

\section{Synthesis of the flow part of the turbine}

The dimensioning of the elements from the flow part of the turbine is performed by the sequential application of the two interrelated tasks: synthesis of the geometry of each element and analysis of the flow through it. Based on the developed methodologies, the CRFTAD computer software system was created. A basic requirement in the design of the flow part of

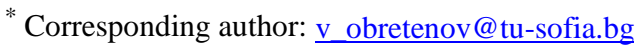


the turbine is to ensure consistency in the kinematic characteristics of the flow of the guide unit outlet and the runner inlet. The guidance device forms a rectangular jet that attacks the runner blades in a sector determined by the value of the active angle (in which water attacks the runner blades at the first passage).

\subsection{Determination of the basic parameters of the turbine}

An approach similar to that used to determine the basic parameters of other types of turbines is applied [3]. On the basis of the statistical analysis of data for cross flow water turbines, which have proved to be effective in operating conditions, regression dependencies have been determined, enabling the values of some of the basic parameters of these turbines to be estimated in advance. The calculation inputs are the estimated discharge $Q$ and turbine head $\mathrm{H}$, as well as their minimum and maximum values. The rotational speed, the main diameter, the diameter of the inlet and the width of the nozzle are calculated, the estimated value of the efficiency is estimated, the mass of the turbine and several other technical and economic indicators are calculated too [4]. The calculations are made for three variants, referring to the calculated and two more adjacent synchronous rotational frequencies, and on this basis, a decision is made for a grounded choice of variant.

\subsection{Synthesis of the guiding device}

The guiding device is a rectangular nozzle to which the regulating device is integrated. The flow direction at the nozzle inlet can be horizontal, vertical or inclined. In this particular case, an inclined or horizontal nozzle and a cylindrical regulating device are applied [4].

The guiding device is designed to convert water energy completely into kinetic energy, ensuring a uniform flow distribution within the active angle (it varies for different operating modes) and a constant attack angle of the runner, as well as to regulate the discharge and with that the power of the turbine, respectively. The synthesis of the geometry of the guiding device is performed according to the procedure described in detail in [4].

Figure 1 shows, in graphical form, the result of calculating an inclined nozzle with regulating device for a model water turbine.

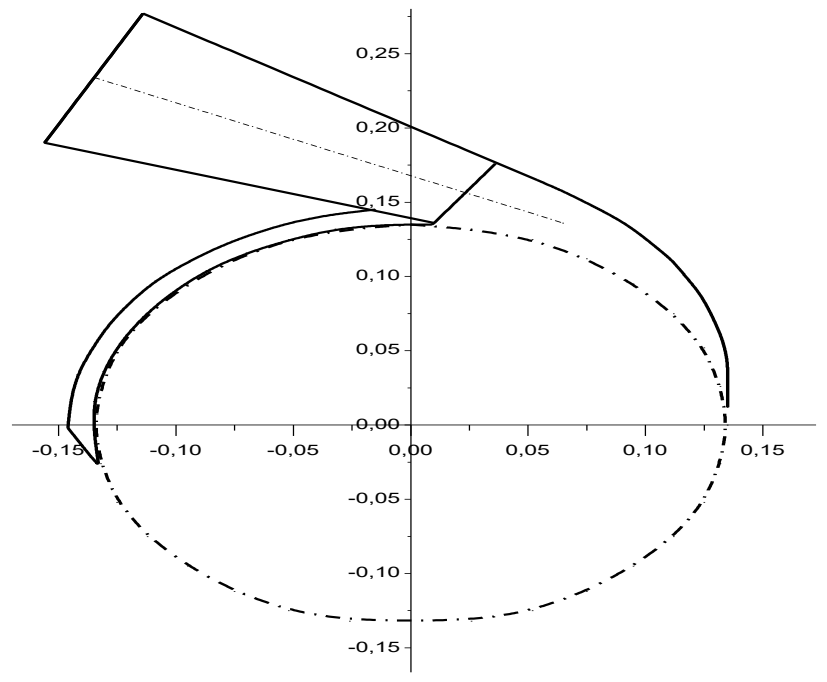

Fig. 1. Nozzle and guiding device. 


\subsection{Synthesis of the runner}

For low-cost cross flow turbines, the blades are usually made as part of a cylindrical surface of constant thickness. They are easily manufactured using a cylindrical tube of suitable diameter and thickness.

For higher efficiency turbines, a methodology is used to design optimally the turbine blade system. The control parameters are the values of the inlet angle $\beta_{1}$, the number of blades $z$ and the so-called form parameter $m$. The idea of using it is based on a method of designing the blades of Francis water turbines [3], in which the form for the transformation of energy from the inlet to the outlet of the blade is specified. Here, the parameter $m$ influences the variation of the angles of the blade from inlet to outlet, which is important from the point of view of the energy conversion process for both the first and the second passage of water through the blade system of the runner. The variation of the angles of the blade $\beta_{i}$ from the inlet to the outlet is set by the fractional-rational function [5]:

$$
\bar{\beta}_{l}=\frac{\beta_{1}-\beta_{i}}{\beta_{1}-\beta_{2}}=\frac{1-\bar{r}}{1-\bar{d}+\left(\frac{1}{m}-2\right)(\bar{r}-\bar{d})},
$$

where $m=\frac{\beta_{1}-\beta_{s}}{\beta_{1}-\beta_{2}}$ is so-called form parameter; $\beta_{1}$ is the angle of the inlet of blade; $\beta_{2}$ is the angle of the outlet of blade; $\beta_{\mathrm{s}}$ is the value of the blade angle at the midpoint along its meridional length; $\bar{r}=r_{i} / r_{1}$ is the relative current radius $\left(r_{1}\right.$ and $r_{2}$ are the radii of the inlet and outlet of the blade) and $\bar{d}=D_{2} / D_{1}$ is the so-called diameter ratio (the ratio of the outlet to the inlet diameter of the runner).

The value of the inlet angle of the blade $\beta_{1}$ is important not only in terms of the energy exchange in the runner, but also to ensure effective interaction and coherence with the turbine nozzle. Experimental studies [2, 5-7] show that the number of blades $z$ also significantly affects the efficiency of the turbine workflow. The values of the basic levels of the three factors $-m, \beta_{1}$ and $z$, as well as the intervals of variation are determined on the basis of recommendations in the specialized literature $[2,4,5]$, results of experimental studies carried out in the laboratory of hydropower and hydraulic turbomachinery at the TU-Sofia [8], as well as results of numerous numerical studies in the development of real cross flow turbines. To determine the optimum values of the three parameters, a symmetric plan is used [9] with a number of points on the carrier 14. In the points of the plan, the blades' hydraulic losses are determined. The optimization problem is solved by the complex method of M. Box. The total minimum of the objective function is found after multiple calculations at different starting points and comparison of the obtained values [4]. The friction losses and the output velocity are taken into account to determine the values of the objective function. After determining the coordinates of the skeletal line, the coordinates of the profile are calculated on the front and back sides of the blade, with the profile being the same in blade width (two-dimensional task). There are two options:

- For turbines with power up to $200 \mathrm{~kW}$, the blades are of constant thickness and corrections are made only in the area of the inlet and outlet edges;

- For higher power turbines, there are higher requirements; the blades are profiled by setting the thickness function $\delta=\delta(1)$, which is used to calculate the coordinates on the front and back sides. 


\subsection{Working chamber and draft tube}

For calculating the dimensions of the working chamber and the draft tube (where used), the recommendations of the specialized literature and the results of the experimental studies carried out $[2,10]$ are applied.

\subsection{Flow analysis in the flow part of the turbine}

For the express evaluation of the efficiency of the synthesized flow part, known computational schemes are applied $[4,6]$. The ANSYS software system is used to study in detail the flow characteristics.

Figures 2 and 3 show the results of calculating the flow characteristics (velocity and pressure distributions) in the flow part of the model cross flow water turbine (B30-A: $Q=230 \mathrm{l} / \mathrm{s} ; H=6 \mathrm{~m}$ ).

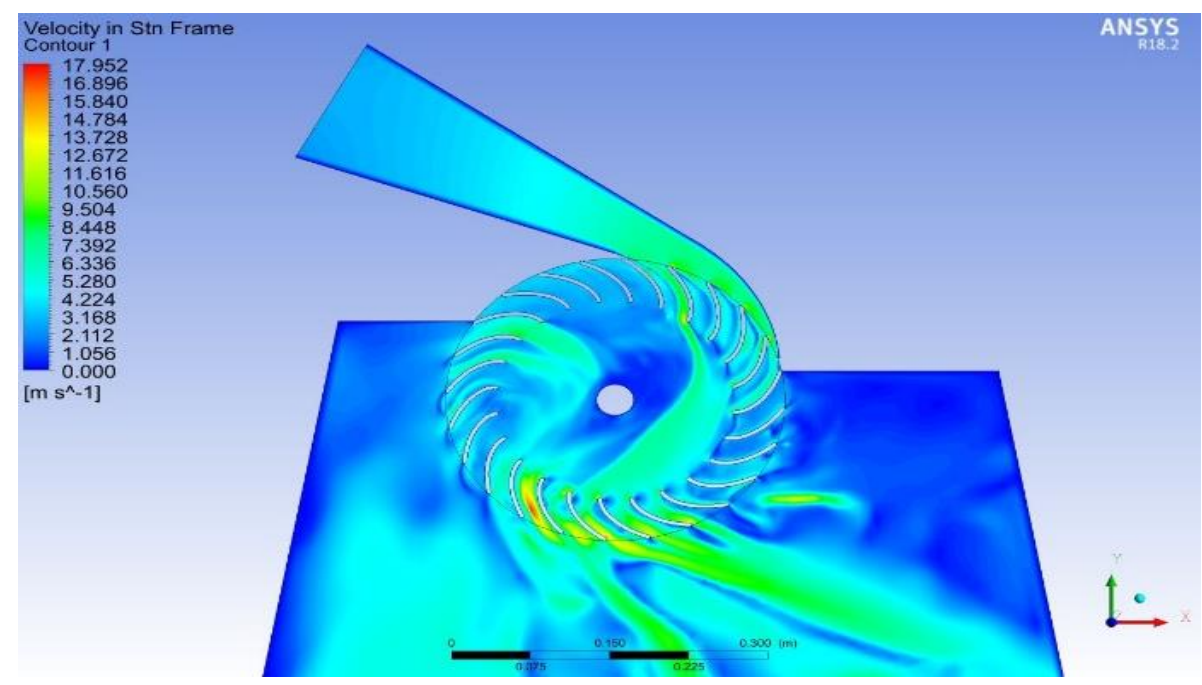

Fig. 2. Velocity distribution.

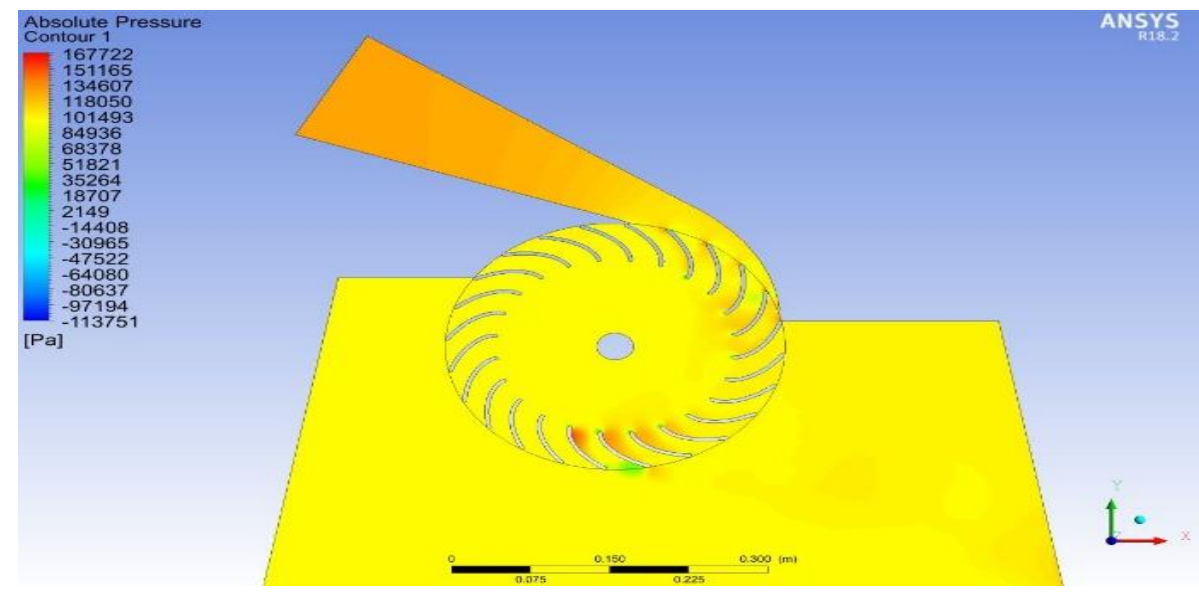

Fig. 3. Pressure distribution. 


\section{Model studies}

Model studies are known to be important both for validation of the developed methods for calculating water turbines and for predicting the characteristics of the original turbines. The first test stand for cross flow water turbines was put into operation in the laboratory of the Department of Hydraulic Machinery in 1984. With the help of this stand, until 2000, a series of water turbines of this type were developed and installed in seven small hydropower plants in Bulgaria. In 2006, a new test stand for model studies of cross flow turbines was put in operation at the new Hydropower and Hydraulic Turbomachinery Laboratory [8]. A scheme of this stand is shown in figure 4.

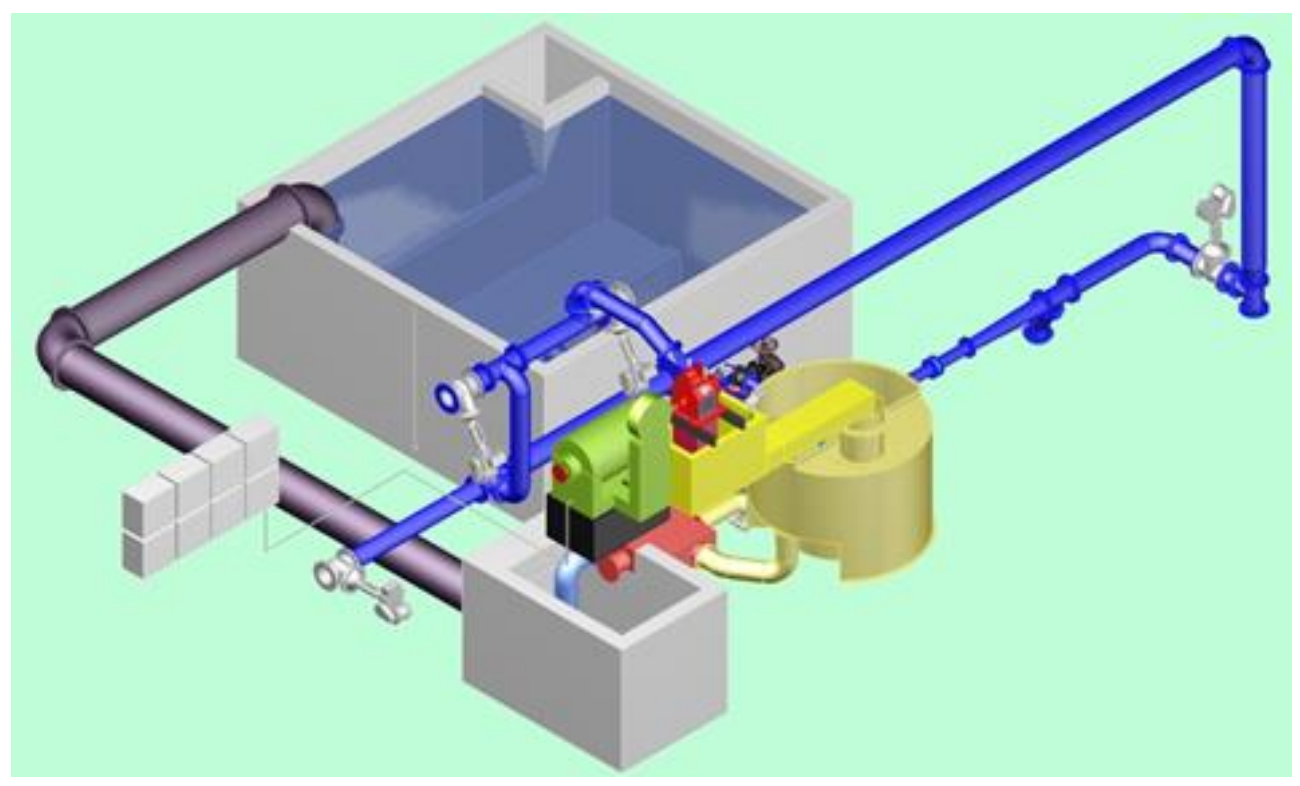

Fig. 4. Test stand for model studies of cross flow turbines.

A wide range of studies have been carried out at this stand [2, 4] aimed at improving the elements of the flow part of the cross flow turbines and verification of the capabilities of the developed methods of calculation. Figure 5 shows a hill diagram of a model cross flow turbine with $\mathrm{B} 5 \mathrm{~N}$ runner with diameter $D_{1}=0.32 \mathrm{~m}$. 


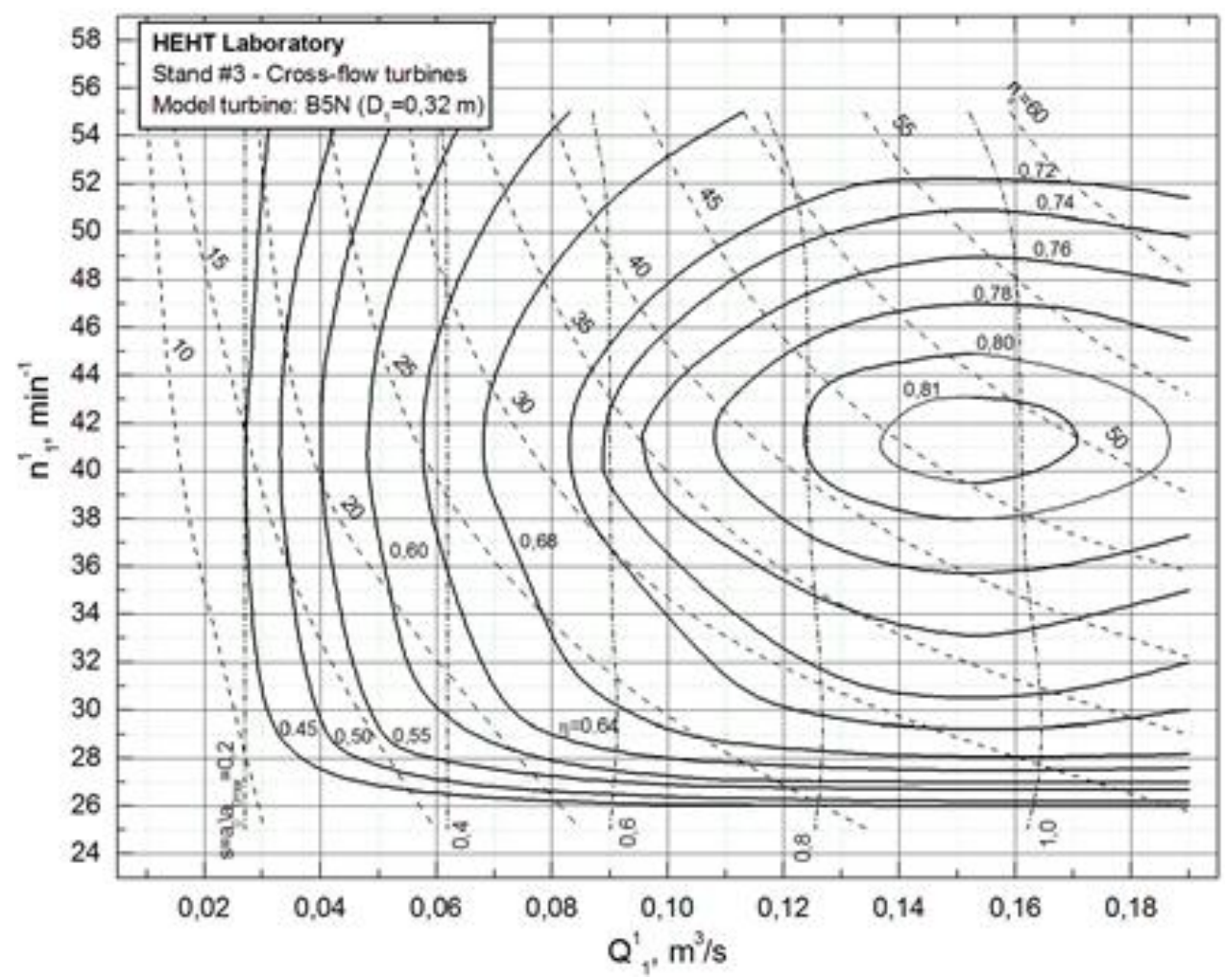

Fig. 5. Model universal characteristic.

Figure 6 shows results of an experimental study of the dimensionless velocity distribution and pressure in the plane of symmetry of the nozzle for two modes of operation: for values of the speed factor $\left(n_{1}^{1}=\frac{n D_{1}}{\sqrt{H}}\right) 33$ and $41 \mathrm{~min}^{-1}$. The dimensionless velocity and pressure values are obtained as a ratio of the real values to those of the nozzle inlet.

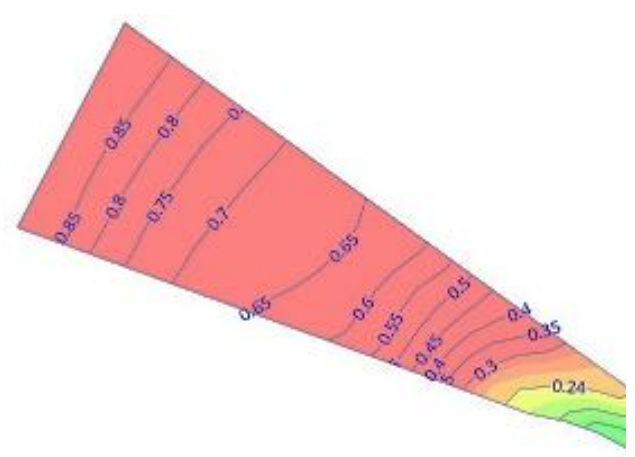

$n_{11}=33 \min ^{-1}$

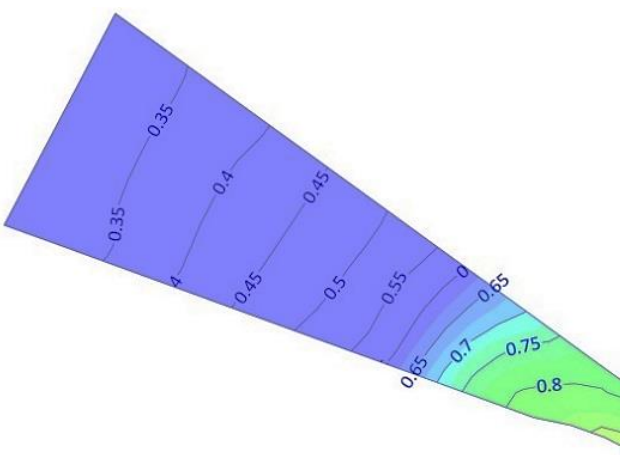

$n_{11}=33 \min ^{-1}$ 


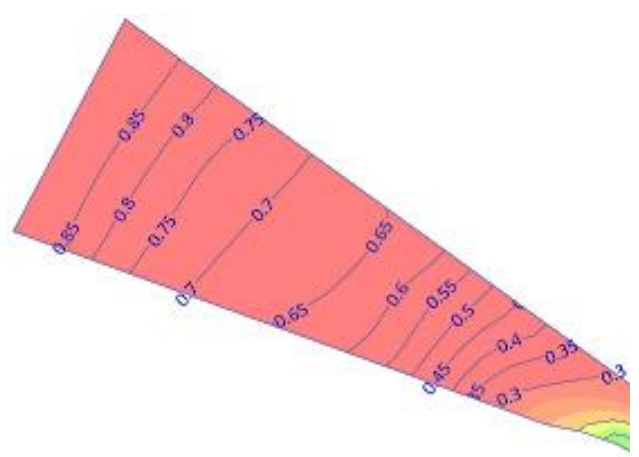

$n_{12}=41 \min ^{-1}$

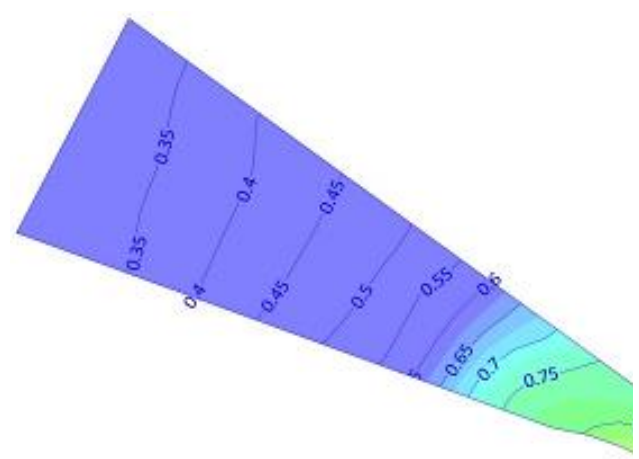

$n_{11}=41 \min ^{-1}$

(a)

(b)

Fig. 6. Distribution of the pressure and the velocity in the turbine nozzle.

\section{Design features}

The guiding device is designed as a welded structure. The connection to the penstock is via a transition element. The regulating device is of sectoral type (Figure 1) and its dimensions are in line with those of the nozzle and impeller. Its bearings are mounted in the turbine housing. Its driving system is electromechanical.

The runner consists of two discs, between which the blades are mounted - figure 7 (a) (Sevlievo HPP). In cases where the runner has a larger width, intermediate discs are also used - figure 7 (b) (Gashnya HPP).

The working chamber of the cross flow turbine must be of such size and shape so as to ensure efficient escape of water by the runner. In this case, it is a welded structure and the bearing bodies and the driving system of the regulator are mounted on it.

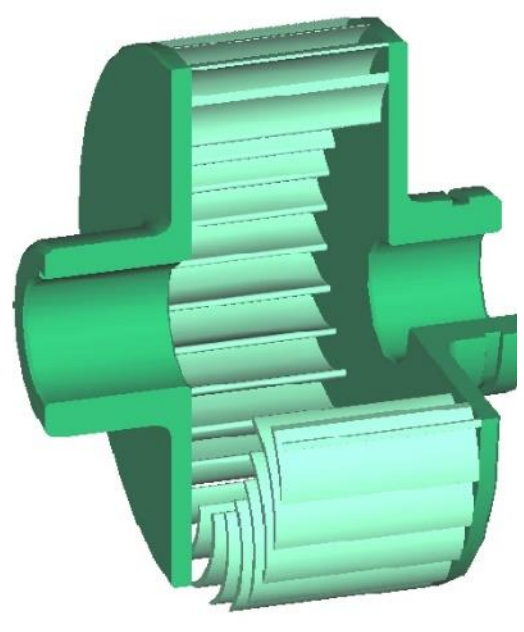

(a)

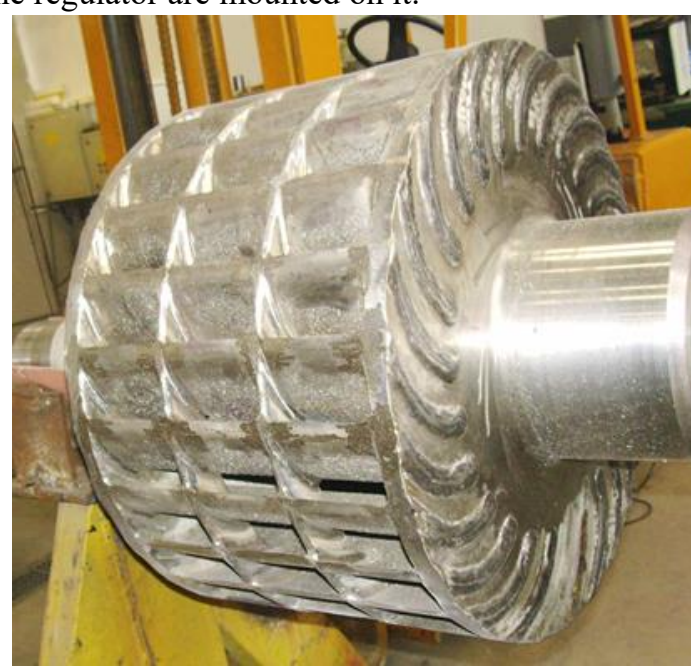

(b)

Fig. 7. Runners: without intermediate disks (a); with intermediate disks (b). 
The use of a draft tube is necessary for low-pressure cross flow turbines and in cases where the tail water after the runner is at a greater distance (for example, when the turbine is used in drinking water systems). In the design of turbines with submerged draft tubes, it is necessary to use an air valve that connects to the working chamber and maintains a constant pressure therein to allow the impeller to rotate in air (figure 8).

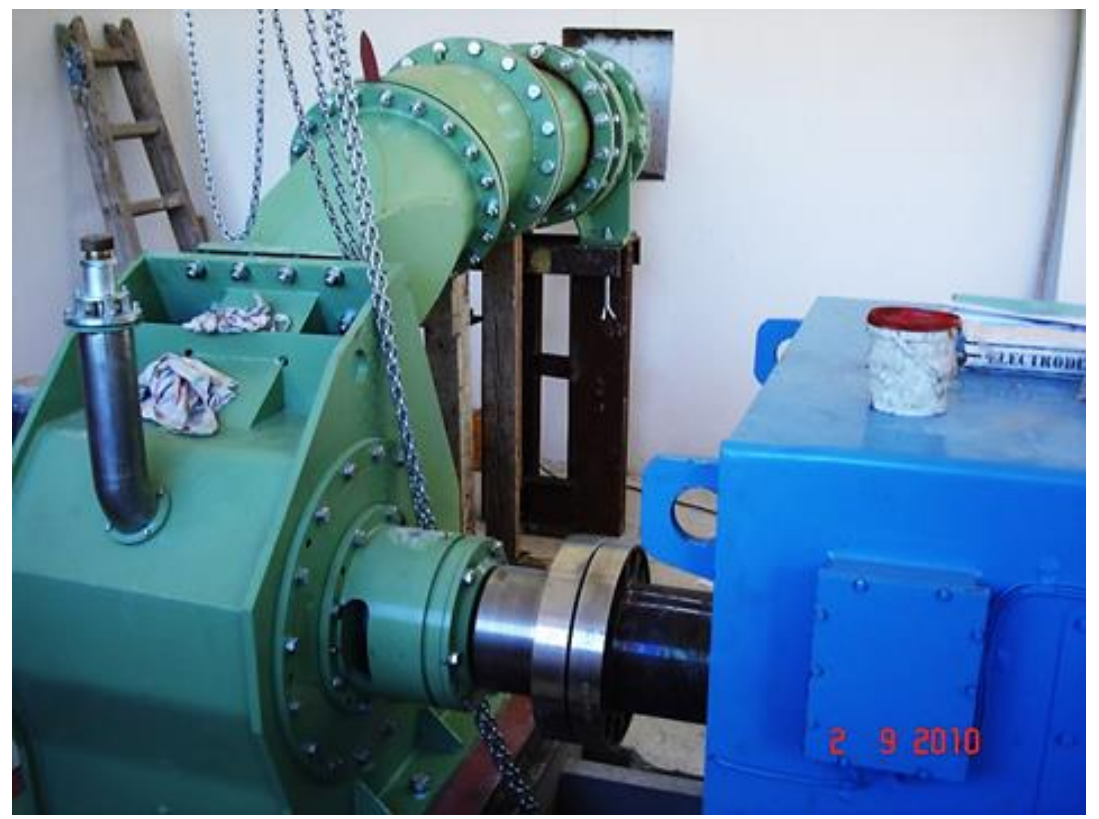

Fig. 8. Hydropower unit (Tufcha 1 HPP).

\section{Application of cross flow turbines in small hydropower plants in Bulgaria}

In cooperation with the Proturbo Ltd. company, since 2000, 26 cross flow turbines have been designed for 16 small hydropower plants in Bulgaria. The turbines have heads ranging from 22 to 142 meters and power up to $500 \mathrm{~kW}$. Figure 8 shows a hydropower unit with a cross flow water turbine from Tufcha 1 HPP $(P=200 \mathrm{~kW})$ in the process of installation in the machine room. In cases where the turbine operates at low head and high flow rates, the rotational speed value of the turbine is low and this requires the use of a multiplier gearbox between the turbine and the generator. The purpose is to increase the rotational speed of the generator. The advantage of such a scheme is the possibility to use serial asynchronous generators with smaller dimensions and mass, which reduces the cost of the hydropower unit. An example of such a hydropower unit is shown in figure 9 (Enigma HPP; $H=22 \mathrm{~m}$, $\left.Q=1.2 \mathrm{~m}^{3} / \mathrm{s}\right)$. 


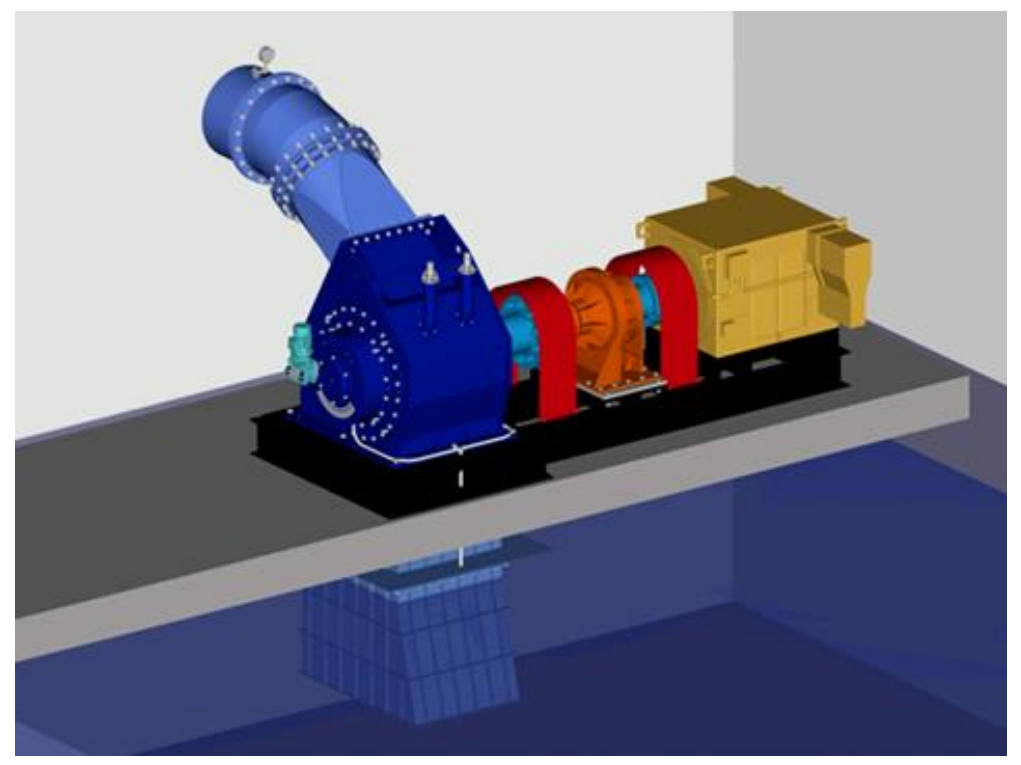

Fig. 9. Hydropower unit with multiplier.

Figure 10 shows the dependencies of the generator power $(\mathrm{Pg})$ and the inlet pressure $\left(p_{1}\right)$ of the two hydropower units at Barzi vir HPP on the relative opening $\left(a_{0}{ }^{*}\right)$ of the turbine regulating device [4]. It should be kept in mind that in this case only the maximum value of the power of the turbine shaft $(150 \mathrm{~kW})$ is guaranteed, and as can be seen from figure 10 , this value is exceeded with the generator power (that is, even with the energy losses in the asynchronous generator).

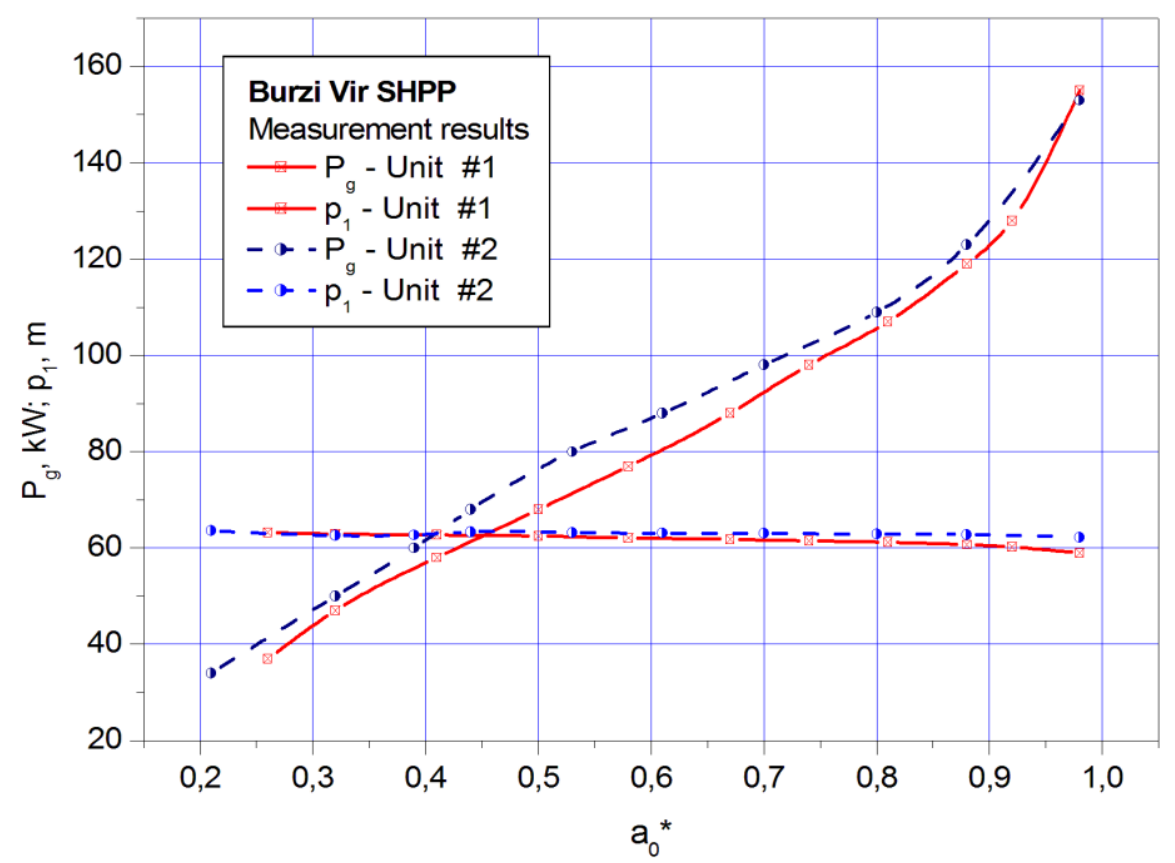

Fig. 10. Working characteristics of cross flow turbines (Barzi vir HPP). 


\section{Conclusion}

The main results obtained after the studies are expressed in the following:

1. Methods and computer programs have been developed for calculating the elements of the flow part of a cross flow turbine.

2. Verification of the developed methods and programs for calculating the flow part of cross flow turbines has been carried out, and model and full-scale studies with turbines sized by these methods have been carried out.

3. A stand has been set up to carry out model studies of cross flow water turbines in accordance with the requirements of the standard.

4. Cross flow turbine designs have been developed and implemented in 23 small hydro power plants in Bulgaria.

\section{References}

1. https://ossberger.de

2. T. Tsalov, Research and development of cross flow water turbines PhD Thesis Technical university of Sofia, Sofia, Bulgaria, 2015

3. V. Obretenov, Water turbines (Sofia: Ekoprogres), 2008

4. V. Obretenov, Increasing the effectiveness of the working process of the active water turbines (Sofia: Ekoprogres), 2012

5. V. Obretenov, Optimization of cross-flow water turbine Proceedings of the 26th Israel conference on mechanical engineering, 21-22 May 1996, Technion city, Haifa, Israel, 1996

6. B. Glezerov, Cross flow turbine and its application in small hydroelectric stations, VIGM proceedings, 18, 1954, Moscow

7. W. Scheer, Untersuchungen an einer Durchstrom-Versuchsturbine der Bauart Banki, 1981 (VDI - Berichte No424)

8. V. Obretenov and Tsalov T 2016 The new hydraulic laboratory at the Technical University of Sofia, Proceedings of IX international conference Hydraulic machines, hydraulic drives and hydro and pneumatic automation. Current status and development prospects, 9-10 June 2016, Saint Petersburg

9. I. Vuchkov and Stoyanov S 1980 Mathematical modeling and optimization of technological objects (Sofia: Technika)

10. V. Obretenov, Experimental investigation of cross-flow turbine Proceedings of the 25th Israel conference on mechanical engineering, 25-26 May 1994, Technion city, Haifa, Israel 